\title{
UMA INVESTIGAÇÃO E UMA PROPOSIÇÃO SOBRE O CONCEITO E O USO DO VALOR JUSTO
}

\section{A STUDY AND PROPOSAL ABOUT THE CONCEPT AND USE OF FAIR VALUE}

\author{
SÉRGIO DE IUDÍCIBUS \\ Professor Livre-Docente do Mestrado de Ciências Contábeis e Atuariais \\ da Pontifícia Universidade Católica de São Paulo \\ Professor Emérito da FEA/USP \\ E-mail: siudicibus@osite.com.br
}

\author{
ELISEU MARTINS \\ Professor Titular do Departamento de Contabilidade e Atuária \\ da Faculdade de Economia, Administração e Contabilidade \\ da Universidade de São Paulo - Campus Capital \\ Presidente do Conselho Curador da Fipecafi \\ E-mail: eliseumartins@terra.com.br
}

\section{RESUMO}

Trata o presente artigo de uma investigação, no sentido de análise, do conceito do Fair Value (Valor Justo), tão debatido nos anos mais recentes e que promete ser, se generalizada sua aplicação nas demonstrações contábeis, uma verdadeira revolução valorativa. No decorrer do trabalho são analisadas, resumidamente, no que se refere aos aspectos mais importantes, as disposições e conceituações sobre Valor Justo apresentadas pelo IASB (International Accounting Standards Board), pelo FASB (Financial Accounting Standards Board) e pelas Normas Brasileiras. A análise efetuada tem um caráter inicialmente semântico, no sentido de expressar, da forma mais clara possível, o sentido das palavras contidas nas conceituações. Em seguida, é feita uma análise qualitativa, visando extrair e avaliar o efetivo impacto das conceituações no avanço das prăticas contábeis. Inicialmente, é importante ressaltar que a conceituação de Valor Justo é bastante antiga. Em 1939, Kenneth MacNeal, em seu pioneiro trabalho, Truth in Accounting, já definia a expressão, de forma brilhante; na verdade, falava em fair and true, atribuindo às valorações, sempre, um significado econômico. A discussão sobre Valor Justo acentuou-se sobremaneira, ganhando até contornos sensacionalistas, a partir do SFAS, 133, emitido pelo FASB em 1998. Através da análise e investigação assim procedidas, é avaliada, por comparação, a eficácia e "justeza” do conceito, ou melhor, conceitos, de Valor Justo em face dos critérios de Custo Histórico, Custo Corrente de Reposição e outros, já praticados há mais tempo pelos contadores. Sugere-se, ao final, um período de experimentação com informações complementares ao modelo tradicional, e não a pura e simples substituição deste último, permitindo então à Contabilidade Positiva o papel de, mediante suas pesquisas empíricas, avaliar a relação entre a utilidade e o custo dessas alternativas antes de qualquer precipitada decisão.

Palavras-chave: Valor; Conceitos Alternativos de Avaliação e Mensuração.

\section{ABSTRACT}

This paper presents an analytic study about the concept of Fair Value, which has been much debated in recent years and promises to be, if its application becomes generalized in financial statements, a true revolution in techniques of valuation. This work briefly analyzes the most important aspects, determinations and concepts about Fair Value, presented by IASB, FASB and Brazilian rules. First, the analysis assumes a semantic character, so as to express the meaning of the words included in the concepts as clearly as possible. Next, a qualitative analysis tries to extract and assess the actual impact of concepts on the advancement of accounting practices. Initially, it should be emphasized that the Fair Value concept goes back quite a long time. In 1939, Kenneth MacNeal, in his pioneering work Truth in Accounting, defined the concept brilliantly; in fact, he talked about fair and true, always granting an economic meaning to valuations. The discussion about Fair Value has attracted increasing intention and gained sensationalistic dimensions since SFAS 133, issued by FASB in 1998. Then, we assess the efficacy and "fairness" of the concept or, better, concepts of Fair Value in comparison with Historical Cost, Replacement Cost and other concepts, which accountants have practiced for a long time. Finally, we suggest a trial period with information. that complements and not simply replaces the traditional model. This allows Positive Accounting to play the role, through empirical research, of evaluating the cost-benefit relation of these alternatives before any precipitated decision is made.

Keywords: Value; Alternative Valuation and Measurement Concepts. 


\section{INTRODUÇÃO}

A Contabilidade, ao longo de sua evolução histórica, que data de cerca de 4.000 anos, tem procurado, através de seus teóricos e praticantes, adaptar-se às circunstâncias e exigências do mercado para o qual desenvolve e aplica suas normas.

A procura por um modelo de avaliação de ativos e passivos tem sido, sempre, um dos assuntos mais candentes e polêmicos. Como a Contabilidade nasceu gerencial, veja ludícibus, Martins e Carvalho (2005), a ênfase recaiu, inicialmente e por muito tempo, na mensuração de desempenho, ou seja, primariamente, no dimensionamento do quanto a receita superava a despesa. Essa era a medida principal de sucesso ou insucesso gerencial.

A teoria do patrimônio líquido conhecida como Teoria do Proprietário, apropriou-se prontamente da premissa e, em última análise, o sucesso de uma entidade era mensurado e ainda o é hoje, em parte, nas entidades de menor dimensão, pelo que acresce ao bolso do proprietário, em dinheiro, após ter recebido as receitas e pago todas as despesas.

Com a evolução das instituições econômicas e sociais e da complexidade e quantidade das operações efetuadas pelas entidades, a teoria do proprietário revelou-se insuficiente para abarcar todas as dimensões contábeis, tendo surgido várias teorias, como a da Entidade, a dos Fundos, a dos Interesses Residuais dos Acionistas Ordinários, a do Comando e outras, que completam e enriquecem o pano de fundo do entendimento da Contabilidade, sendo que todas têm facetas interessantes a oferecer; mas nenhuma delas abarca todas as peculiaridades contábeis, embora a Teoria da Entidade seja, até o momento, a mais completa. A esse respeito veja ludícibus (2004).

Essa evolução toda foi facilitada pelo método das partidas dobradas, genial invenção de quem nunca se soube a autoria; uma forma de poder acumular milhares de operações diárias ou mensais e dar-Ihes um tratamento sistêmico muito superior à simples diferença entre patrimônios líquidos apurados em dois balanços sucessivos, que era a prática comum até o aparecimento, provavelmente no século XII, do citado método.

Possivelmente, se não tivesse sido inventado o método das partidas dobradas e se a Contabilidade se resumisse, até hoje, ao levantamento minucioso de inventários de bens, direitos e obrigações, em determinadas datas, o custo histórico não teria prevalecido como forma tradicional de avaliação de ativos e passivos (e, por diferença, do patrimônio líquido). Haveria, quase com certeza, a tendência de se avaliar a valores de mercado; não se consegue discernir, todavia, se seriam valores de compra ou de venda.

A utilização do método das partidas dobradas favoreceu a utilização de custos históricos, pela maior facilidade de acumulação e por serem os objetivamente existentes e comprováveis na hora do registro da operação. Além do mais, o custo histórico e mais os princípios da realização da receita e da confrontação das despesas com as receitas (regime de competência) atrelam o resultado contábil a fluxos de caixa já ocorridos ou, então, a ocorrer, mas desde que derivados de fatos geradores contábeis acontecidos; e essa amarração entre lucro e caixa se presta fortemente à avaliação do desempenho das transações ocorridas e também fortemente à accountability. Por outro lado, transforma os ativos não monetários (estoques e imobilizado, principalmente) em depósitos de quantias investidas em caixa a serem cotejadas com as receitas representativas de caixa a ser recebido no futuro.

É claro que, por várias vicissitudes econômicas vividas por diversos países em épocas distintas, o custo histórico foi sendo adaptado para custo histórico corrigido (pela variação de algum índice geral de preços), tendo surgido, também, autores e até práticas defendendo o uso do custo corrente de reposição, por ser superior ao custo histórico para finalidades gerenciais. Esse último, eventualmente, foi ainda aperfeiçoado pela aplicação dos coeficientes de variação geral de preços, a fim de se poder comparar balanços com seus valores de reposição de datas distintas, colocados, porém, numa moeda de capacidade aquisitiva única. Até valores de saída já foram preconizados, no passado, como base geral de avaliação, sem muita aceitação à época.

De certa forma, o enforcement do Valor Justo dá um enorme salto sobre as formas tradicionais de avaliação, passando por cima das alternativas mais conhecidas, a fim de aportar no outro lado do rio. O que se tratará, nos próximos itens, é de tentar averiguar se esse salto, extremamente corajoso, apresenta riscos maiores do que os benefícios ou, pelo menos, se não deveria ser dado com mais precauções.

Raros trabalhos têm surgido para uma análise conceitual do Valor Justo, daí o presente estudo. Dentre os já divulgados, salientamos "Valor Justo" em Contabilidade, apresentado no XVI Congresso Brasileiro de Contabilidade de 2000, de autoria dos Profs. Lázaro Plácido Lisboa, Fábio Moraes da Costa e do José Alexandre Magrini Pigatto.

É evidente que, dado o caráter altamente subjetivo das análises e hipóteses que serão feitas e avançadas, este trabalho deve recair na categoria de investigação de caráter teórico-opinativo. Deve sua utilidade ser avaliada mais pelas discussões que pode propiciar do que pelas suas eventuais conclusões, as quais devem ser observadas com bastante cuidado, levando-se em conta as limitações da metodologia utilizada. 


\section{CONCEITUAÇÃO DO IASB: UM RESUMO}

A análise será realizada a partir das normas do IASB e das inserções sobre Valor Justo contidas no livro editado pela KPMG intitulado Insights into IFRS, edição 2005/2006, editado pela Thomson (baseadas principalmente no IAS 39). Assim é que, na página 37 do referido livro, se assevera que os IFRSs requerem que as demonstrações contábeis devem ser preparadas numa base de custo histórico modificado, com uma ênfase crescente no valor justo. Em seguida, valor justo é definido da seguinte maneira: Fair value is the amount for which an item could be exchanged or settled between knowledgeable willing parties in an arm's length transaction'.

A primeira dificuldade é entender ou traduzir para o português, de forma adequada, a definição em inglês. Poder-se-ia tentar traduzir por: Valor Justo é a importância pela qual um item poderia ser trocado ou acertado entre participantes desejosos e com conhecimento, numa transação "do comprimento de um braço". Essa tradução literal, todavia, não rende a idéia por detrás da definição, em inglês. Talvez se pudesse traduzir por: Valor Justo é o montante pelo qual um determinado item poderia ser transacionado entre participantes dispostos e conhecedores do assunto, numa transação sem favorecimento. Com variantes, essa tem sido a tradução prevalecente no Brasil. O Dicionário de termos de Contabilidade, de autoria de Sérgio de ludícibus e José Carlos Marion, Atlas, 2001, define Valor Justo como: Importância pela qual um ativo poderia ser transacionado entre um comprador disposto e conhecedor do assunto e um vendedor também disposto e conhecedor do assunto em uma transação sem favorecimento. Nota-se que não há diferenças importantes entre as definições aceitas. Mais recentemente, todavia, o Valor Justo tem sido empregado intensamente na divulgação de instrumentos financeiros, assumindo conotação mais detalhada daquela anteriormente definida. Assim, esse valor não está restrito à avaliação de ativos. Além disso, pode-se aplicá-lo também aos passivos, registrados ou não. (MARTINS, 2001, p.120).

Além da dificuldade semântica, o conceito, da forma como está definido, apresenta, indubitavelmente, características complexas. A primeira é quando afirma que Valor Justo é a importância pela qual um determinado item "poderia" ser transacionado. O termo poderia coloca o avaliador numa situação indeterminada, num limbo conceitual com tendência a levá-lo diretamente para o inferno da indefinição. Não se definia, até muito recentemente, se era um valor de entrada ou de saída. Um mercado de compra ou de venda. Claro que mercado é mercado, tanto compradores quanto vendedores podem transitar por ele. Mas, se a primeira exteriorização do conceito, na prática, tem sido feita através da obtenção de um valor de mercado, por que não definir, desde logo, Valor Justo como Valor de Mercado? Veja-se como a resposta talvez não justifique essa diferenciação. O limbo conceitual que a definição, com sua incerteza, coloca, é propiciar interpretações heterodoxas e paroxísticas quando o valor de mercado não existe. Até modelos matemáticos e matriciais extremamente complexos têm sido pensados a fim de calcular esse Fair Value em tais condições! Ou seja, por se querer atribuir valor a um elemento patrimonial que não tenha preço de mercado, adotou-se a expressão valor justo.

Exemplos de ativos e de passivos, segundo o IASB, cujos saldos contábeis são determinados com referência a mensurações baseadas em custo histórico, mesmo subseqüentemente ao registro inicial (ignorando ajustes por "impairment") são os seguintes: terrenos, imóveis em geral, instalações e equipamentos, goodwill adquirido, ativos intangíveis não negociados frequentemente no mercado (marcas, patentes, direitos autorais), investimentos permanentes não reavaliados, empréstimos e contas a receber originados pela entidade mantidos até a data de seus vencimentos, bem como exigibilidades financeiras outras que não as que têm que ser mensuradas pelo Valor Justo.

Por outro lado, os saldos contábeis dos ativos e passivos a seguir enunciados são ou podem ser baseados no valor justo, subseqüentemente ao registro inicial:

Todos os derivativos, ativos financeiros e exigibilidades financeiras dados como prontos para negociação e todos os ativos financeiros que forem classificados como disponíveis para serem colocados mais à frente para venda são avaliados a valor justo.

Ativos Biológicos devem ser mensurados pelo valor justo menos custos para vender.

Conjuntos inteiros de imóveis, instalações e equipamentos podem ser reavaliados pelo valor justo mediante a observância de certas condições.

Certos ativos intangíveis (situações muito raras, pois foram previamente registrados contabilmente e com valor de mercado objetivamente definido por transações freqüentes) podem ser reavaliados pelo valor justo.

Investimentos em imóveis podem ser mensurados pelo valor justo.

Em primeiro lugar, nota-se que a avaliação pelo valor justo não é um procedimento que deva ser aplicado a todos os ativos e passivos. Assim, como critério geral de avaliação, falha por não alcançar uma homogeneidade de classificação.

Em segundo lugar, alguns itens, que inicialmente foram designados como devendo ser avaliados pelo Custo, 
também podem ser avaliados pelo Valor Justo, sob certas condições.

Um dos casos típicos é o dos ativos intangíveis. O IASB destina-Ihes, inicialmente, como critério geral, a avaliação ao Custo. Entretanto, se existir um mercado ativo para tais itens, poderão ser reavaliados pelo Valor Justo (são dados como exemplos pelo próprio IASB: direitos de exploração de serviços de táxi, quando negociados livremente e direitos de pesca, se também negociados livremente).

Já quando se trata da perda de valor de ativos (impairment), o IASB bem recentemente define valor justo como o valor de venda de um ativo ou de uma unidade geradora de caixa numa transação sem favorecimento etc. (IAS 36).

Verifica-se que, como em alguns outros procedimentos ditados pelo IASB, FASB e até pelas Normas Brasileiras, se configura um problema de metodologia. Edwards e Bell (1961) já haviam explorado os aspectos da avaliação de ativos e passivos de forma exaustiva e em várias configurações de variações de preços. O traço metodológico mais forte que se nota no trabalho deles é a escolha de um único critério geral de avaliação para ativos e passivos. Somente quando as dificuldades de mensuração de certos itens, pelo critério geral preconizado, fossem insuperáveis, é que se recorreria a mensurações alternativas. Inversamente, na regulação contábil dos citados órgãos, às vezes existem muitas exceções à regra geral, não só no assunto do Valor Justo como em outros.

Sabe-se que, resumindo e colhendo as facetas fundamentais do seu texto, a base geral de avaliação preferida por Edwards e Bell era o Custo Corrente (em sua forma mais avançada, corrigido, entre datas, pelas variações do poder aquisitivo médio geral da moeda).

Custo corrente poderia ser definido, de forma simples, como a quantia que se teria de desembolsar, no mercado, para adquirir um bem no mesmo estado em que se encontra o ativo objeto de avaliação. Por exemplo, se, no Imobilizado Tangível, os veículos de trabalho de uma empresa são, diga-se, caminhões GM adquiridos em 1999, o valor corrente (para ser ajustado o ativo após a compra) em 2006 deveria ser quanto se deveria desembolsar por um caminhão nas mesmas condições operacionais em que se encontra o efetivamente incorporado no ativo, mas com a dupla informação: o valor de reposição de um bem no estado de novo diminuído da depreciação acumulada de tal forma que o líquido fosse esse valor de reposição no estado em que se encontra.

É claro que há dificuldades: primeiramente, deve existir um mercado ativo para bens usados; nem sempre é possível. Em segundo lugar, às vezes, o ativo que a empresa utiliza ou fabrica, somente ela o faz. Existe uma terceira dificuldade, que é a de se encontrar um ativo exatamente nas mesmas condições do que está sendo avaliado.

Para a primeira dificuldade, em lugar de tentar achar o valor de recompra do ativo, calcula-se o custo corrente dos insumos contidos naquele ativo. Para a segunda dificuldade, o antídoto é o mesmo. Para a terceira, utiliza-se o valor de um bem equivalente ao que está sendo avaliado, em estado de novo, e se aplica ao mesmo igual percentagem que a depreciação acumulada (sempre medida em termos de efetiva vida útil econômica e não pelos critérios fiscais) representa sobre o valor do ativo avaliado. É evidente que, nessa terceira opção, se estará desviando do conceito puro de custo corrente, para incluir mudança tecnológica. Também se aplicam a esses casos de ativos não encontrados no mercado na mesma situação como estão, em certas circunstâncias, coeficientes de ajuste derivantes da utilização de índices de preços específicos para o ativo avaliado ou, pelo menos, índices que representem a variação de preços de uma categoria de bens mais ampla dentro da qual os em discussão se enquadrariam.

São conceitos de aplicação não tão fácil, admite-se, mas que possuem um mínimo de objetividade e de referência ao mercado. No caso do Valor Justo, quando o valor de mercado não for possível de ser obtido (pela definição, continuaria o problema de qual valor de mercado se trata), entra-se em cálculos extremamente subjetivos, como se verá mais adiante.

\section{DIRETRIZES DA CVM}

Timidamente, a CVM tratou do assunto relativo à divulgação do valor de mercado dos instrumentos financeiros e, conseqüentemente, do Valor Justo (ou melhor, do Valor de Mercado) na Instrução 235, de 23 de março de 1995, exigindo que as companhias que tivessem instrumentos financeiros reconhecidos ou não em seus balanços como ativo ou passivo patrimonial devessem evidenciar, em nota explicativa anexa às demonstrações contábeis e às ITR trimestrais, o valor de mercado desses instrumentos financeiros. Na nota devem constar os critérios e as premissas adotados para determinação desse valor de mercado, bem como as políticas de atuação e controle das operações nos mercados derivativos e os riscos envolvidos.
Após definir o que vêm a ser instrumentos financeiros, ativos financeiros e passivos financeiros, em seu artigo 3o define valor de mercado, para fins da Instrução, como:

I. o valor que se pode obter com a negociação do instrumento financeiro em um mercado ativo, em que comprador e vendedor possuam conhecimento do assunto e independência entre si, sem que corresponda a uma transação compulsória ou decorrente de um processo de liquidação, ou

II. na ausência de um mercado ativo para um determinado instrumento financeiro: a) o valor que se pode obter com a negociação de outro instrumento 
financeiro de natureza, prazo e risco similares, em um mercado ativo, conforme referido no inciso I ou b) o valor presente líquido dos fluxos de caixa futuros a serem obtidos, ajustado com base na taxa de juros vigente no mercado, na data do balanço, para instrumentos financeiros de natureza, prazo e risco similares.

Primeiramente, é interessante notar que a avaliação pelo valor justo limita-se aos instrumentos financeiros e, em segundo lugar, em nota explicativa.

A Instrução não definiu Valor Justo, vindo a fazê-lo posteriormente, na Deliberação 371, de 13 de dezembro de 2000. A Instrução 235 simplesmente aplica aos instrumentos financeiros o valor de mercado, sendo esse o definido em seu art. 3․ Indiretamente, acaba caracterizando as várias formas de mensurar o valor justo, em seus Incisos I e II.

Mais tarde, como se viu, em 2000, na Deliberação 371, de 13 de dezembro de 2000, que se refere à contabilização de benefícios a empregados, em seu item 18, define Valor Justo como

[...] o valor pelo qual um ativo pode ser negociado ou um passivo liquidado entre partes interessadas, em condições ideais e com a ausência de fatores que pressionem para a liquidação da transação ou que caracterizem uma transação compulsória.

A Instrução 235, por ter sido, em nosso meio contábil, bastante tempestiva com relação às normas do FASB e do IASB (é de 1995), teve que ser cuidadosa e limitou a aplicação do valor justo aos instrumentos financeiros e sua evidenciação em nota explicativa. Entretanto, foi bastante avançada ao caracterizar como mensurar o valor de mercado ou as alternativas na falta desse. É evidente a subjetividade das mensurações, principalmente a do item b) do Inciso II.

A tardia definiç̧ão de Valor Justo, contida na Deliberação 371, de 2000, é bastante abrangente, incluindo ativos e passivos em geral e seguindo, embora com palavras diferentes, a definição do IASB. Não são comuns, todavia, as aplicações desse conceito às empresas, com exceção das entidades financeiras, que devem aplicar o marked to market, valor de mercado. (Recentemente, o Banco Central do Brasil emitiu Nota afirmando que, até 2010, todas as entidades financeiras por ele supervisionadas deverão adotar os procedimentos internacionais, o que poderá ampliar o uso do Valor Justo.)

É de se mencionar que o CPC - Comitê de Pronunciamentos Contábeis, recentemente criado no Brasil, está, quando da redação final deste artigo, com uma minuta de impairment de ativos na qual utiliza a seguinte definição: valor recuperável de um ativo ou de uma unidade geradora de caixa é o maior valor entre o valor líquido de venda de um ativo e seu valor em uso. $E$ complementa dizendo que valor líquido de venda é o valor a ser obtido pela venda de um ativo ou de uma unidade geradora de caixa em transações em bases comutativas, entre partes conhecedoras e interessadas, menos as despesas da baixa; e ainda define: valor em uso é o valor presente de fluxos de caixa futuros estimados, que devem resultar do uso de um ativo ou de uma unidade geradora de caixa, ou seja, baseiase no IAS 36 mas usa expressões mais específicas para se referir ao valor justo para fins da verificação e eventual registro das perdas de valor dos ativos (impairment).

Note-se a sutil mas importante diferença com a conceituação do IASB. Lá se fala em amount, na definição do FASB em price. $\mathrm{O}$ apelo ao valor de mercado parece mais forte $e$ imediato na definição do FASB. As outras dificuldades ilustradas e comentadas no caso do IASB permanecem.

E note-se também a explícita referência, a valor de saída, de venda, para a conceituação do Valor Justo, tanto para os ativos quanto para os passivos.

O FASB propõe vários níveis para a mensuração do Valor Justo. Assim, o Nível I requer o uso de preços listados num mercado ativo para ativos e passivos idênticos. A fim de poder usar esse nível, a entidade tem que ter acesso imediato ao mercado (poderia realizar trocas de forma usual).

O Nível 2 requer o uso de preços listados (de cotação) para ativos e passivos semelhantes em mercados ativos. Enquanto no Nível I a entidade não pode fazer qualquer alteração nos preços de cotação, uma entidade pode realizar ajustamentos de preços, conforme necessário, no Nível 2, pois os ativos e passivos são apenas semelhantes, 
não idênticos. Estabelece-se, todavia, que qualquer ajuste precisa ser objetivo. Se não for, ou se não existirem bens semelhantes no mercado ativo, a entidade precisa mensurar o valor justo baseado no Nível 3. Esse nível requer o uso de técnicas de avaliação. O Statement sugere o uso do mercado, lucro e custo, como abordagens, a não ser que a utilização dos três critérios produza esforços e custos indevidos. Se esse for o caso, a entidade vai ter que usar a abordagem que produza a melhor aproximação do valor justo. Os insumos usados para determinar o valor devem ser externos à entidade. A entidade só poderá repousar em informação interna se o custo e o esforço para obter informação externa forem altos demais.

Note-se, assim, o cuidado e o grau de detalhe e profundidade com que o FASB tratou do assunto. As sucessivas imersões nos vários níveis, cada vez mais subjetivos, ilustram as dificuldades que os contadores do presente e do futuro enfrentarão. De um mundo de absoluta certeza, ou pelo menos de aparente certeza, o do custo histórico, temse que dar um salto gigantesco para outro patamar. O que preocupa, além das dificuldades em parte já apontadas, é que se pretende substituir as bases originais de avaliação por outra, totalmente, sem possibilidade de tracking (no sentido de poder ser rastreado, auditado de maneira formal e objetiva, vinculado). Não seria mais cuidadoso e correto simplesmente adotar as premissas mais avançadas em demonstrações suplementares?

O SFAS 133 (Accounting for Derivatives Instruments and Hedging Activities), editado em junho de 1998, mais tarde emendado em alguns aspectos pelo SFAS 138, é um dos documentos mais importantes e polêmicos editados pelo FASB e que toca em cheio o assunto de Valor Justo. (O SFAS 133 emenda e/ou substitui os SFAS 52, 80, 105, 107 e 119).

O SFAS 133 requer que uma entidade reconheça todos os derivativos como ativos ou passivos, nas demonstrações contábeis, e que avalie aqueles instrumentos ao Valor Justo.

A contabilização das flutuações no valor justo de um derivativo (isto é, ganhos e perdas) depende da utilização prevista do derivativo e da designação resultante. Assim:

A) Para um derivativo designado para realizar o hedge da exposição de um ativo ou passivo às variações no seu valor justo, os ganhos ou perdas desse derivativo são reconhecidos nos resultados do período em que a variação ocorreu, juntamente com o cancelamento da perda ou do ganho registrados sobre o item em relação ao qual se fez o hedge. O efeito de tal contabilização é o de refletir nos resultados até que ponto o hedge foi efetivo ou não em proteger as variações do Valor Justo do ativo ou passivo que se pretendeu proteger.

B) Para um derivativo designado para fazer o hedging da exposição ao risco de fluxos de caixa futuros ligados a uma transação prevista (denominada como hedge de fluxo de caixa), a parcela efetiva do ganho ou perda do derivativo é inicialmente reportada como um componente de outros rendimentos glo- bais (ganhos externos) e contabilizada diretamente no patrimônio líquido (other comprehensive income). Subseqüentemente é reclassificada para o resultado quando a transação prevista o afetar. A parcela não efetiva do ganho ou perda é reportada nos resultados, imediatamente.

C) Para um derivativo designado para hedging de risco em moeda estrangeira de um investimento numa operação no exterior, o ganho ou perda é reportado em outro rendimento global (fora dos resultados) como parte do ajuste total da tradução em moeda estrangeira. A contabilização para um valor justo acima descrito se aplica a um derivativo designado como hedge da exposição ao risco de moeda estrangeira de um compromisso não reconhecido de uma empresa ou um título para venda. De forma semeIhante, a contabilização para um hedge de fluxo de caixa acima descrito aplica-se a um derivativo designado como hedge de uma exposição em moeda estrangeira ou a uma transação prevista de moeda estrangeira.

D) Para um derivativo não designado como instrumento de hedging, o ganho ou perda é reconhecido nos resultados no período da variação.

Percebe-se como a trama de conceituação estabelecida pelo FASB é complexa, completa e todos os tipos de entidade, inclusive as de finalidades não lucrativas, estão abarcadas pelas diretrizes do SFAS 133.

O SFAS 142, Goodwill and Other Intangible Assets, editado em Junho de 2001, trouxe substanciais avanços com relação à APB Opinion 17 que regulava, até aquele momento, os assuntos em epígrafe.

Assim, a APB Opinion 17 presumia que o goodwill e todos os outros ativos intangíveis eram ativos que se desgastavam (isto é, tinham vida finita), e, portanto, os valores a eles atribuídos deveriam ser amortizados ao determinar o lucro líquido; a Opinion 17 também estabelecia um prazo máximo arbitrário de 40 anos para tal amortização. Em contraste, o SFAS 142 não presume que tais ativos sejam esgotáveis. Ao contrário, o goodwill e outros ativos intangíveis que têm vida útil indefinida não são mais amortizados, mas sim testados pelo menos a cada ano pelo impairment (perda de substância econômica). Os ativos intangíveis que têm vidas úteis finitas continuarão a ser amortizados durante suas vidas úteis, mas sem a restrição de um prazo máximo arbitrário.

Os padrões anteriores não ofereciam parâmetros suficientes sobre como determinar e mensurar o impairment do goodwill. Como resultante, a contabilidade para o impairment do goodwill não era consistente, e também não comparável, e se traduzia em informações de utilidade questionável. O SFAS 142 introduziu normas específicas para o teste de impairment do goodwill. Este tem que ser testado pelo impairment, pelo menos anualmente, utilizando um processo de dois passos que se inicia com uma estimativa do valor justo da unidade de relatório 
(reporting unit). O primeiro passo é uma investigação para descobrir impairment potencial, e o segundo mensura o valor do impairment, se ele se configurar. Os outros intangíveis (que não goodwill) que não forem amortizados serão também testados pelo impairment pelo menos anualmente, com base na comparação entre seu valor justo e seus valores registrados. OSFAS 142 fornece normas específicas para determinar quais os intangíveis que não serão submetidos ao teste de impairment.

Importante lembrar que o Board considerou que a não amortização do goodwill acoplada com o teste de impairment, avaliando o valor justo da entidade, era mais consistente com o FASB Concepts Statement N.2, Qualitative Characteristics of Accounting Information. É firme crença do Board que o SFAS 142 irá melhorar a qualidade das demonstrações contábeis. O Valor Justo, como se vê, joga um papel importante no teste anual de impairment.

O SFAS 144 estabelece um único modelo contábil, baseando-se na estrutura do SFAS 121, no que se refere aos ativos de longa duração a serem baixados por venda. $\mathrm{O}$ SFAS 121 dispunha sobre impairment de ativos de longa duração, incluindo os que seriam baixados. Entretanto, não se aplicava às operações descontinuadas. Assim, antes do SFAS 144 existiam dois modelos contábeis para que os ativos de longa duração pudessem ser baixados.

O SFAS 144 reconhece uma perda por impairment se a soma dos fluxos esperados de caixa (sem desconto) for menor que o saldo contábil dos ativos e mensura a per- da por impairment como a diferença entre o Valor Justo do ativo e seu saldo contábil.

A fim de determinar o Valor Justo, a norma provê uma abordagem de probabilidade ponderada para poder estimar os fluxos de caixa quando mais do que um curso de ação esteja sendo considerado para recuperar o valor do saldo contábil (consistentemente com o Concept Statement 7).

Dispõe que um ativo de longa duração não deve ser depreciado ou amortizado enquanto estiver classificado como mantido para venda. Adicionalmente, o SFAS inclui as operações descontinuadas na determinação de que os ativos devem ser mensurados pelo saldo contábil ou pelo seu valor justo menos custo para vender, dos dois o menor. Assim, se o valor justo, menos custo de venda, dos ativos de partes de uma entidade (componentes da entidade) for menor que o valor contábil na data em que a empresa determinar que o componente é para ser mantido para venda, uma perda por impairment é reconhecida (e o valor contábil dos ativos é diminuído até igualar o valor justo) e incluída na demonstração de resultados como operações descontinuadas. $A$ depreciação e a amortização de ativos de longa duração da componente são descontinuadas enquanto estiverem esses ativos classificados como mantidos para venda.

O FASB tangencia e aplica o conceito de Valor Justo em muitos outros pronunciamentos, interpretações e documentos vários. Apresentaram-se apenas alguns dos mais importantes.

\section{UMA DECORRÊNCIA DO VALOR JUSTO: A DEMONSTRAÇÃO DO COMPREHENSIVE INCOME}

A Contabilidade, calcada no custo histórico, trabalhou sempre com a conceituação de lucro como diferença entre patrimônios líquidos, após consideração com as transações de capital com os sócios que são: aumento ou diminuição de capital, aquisição e venda das próprias ações ou cotas e distribuição de resultados. Na versão mais rígida, conceito do "all inclusive", todas as demais mutações patrimoniais, que não essas transações de capital com os sócios, devem passar pelo resultado, aí incluídos os ajustes de exercícios anteriores, as subvenções para investimentos etc. Já na versão extrema oposta, a do "operational income", apenas o resultado operacional e recorrente deve ser considerado no resultado do período, com todas as demais mutações sendo refletidas diretamente no patrimônio líquido, inclusive ajustes de provisões "normais", como a para créditos de liquidação duvidosa e para depreciação, ajustes de exercícios anteriores, subvenções para investimento etc. Só que esses registros efetuados diretamente ao patrimônio lá permanecem para sempre, sem nunca mais transitar pelo resultado.

(No Brasil, nossa lei magna contábil, a 6.404/76, das sociedades por ações, adotou posição intermediária: os ajustes normais decorrentes de diferenças entre estimativa e realizado fazem parte do resultado, como a reversão da provisão para créditos de liquidação duvidosa, os "ganhos" ou "perdas" na baixa de ativos imobilizados, que na maior parte dos casos representam depreciações contabilizadas a maior ou a menor anteriormente, bem como as receitas e as despesas não operacionais. Já os ajustes de exercícios anteriores e as reservas de capital vão diretamente ao patrimônio e nunca passam pelo resultado, e a reserva de reavaliação, por força dessa lei e das normas da CVM, também segue esse caminho, tanto na sua constituição quanto na sua realização.)

Porém, dentro dos Princípios do Custo Histórico e da Realização da Receita, há praticamente sempre, no máximo com a exceção dos ajustes de exercícios anteriores e das reservas de capital, correlação entre reconhecimento da receita e incremento do ativo ou redução do passivo; e entre reconhecimento da despesa e redução do ativo ou incremento do passivo. E é bom lembrar que o Princípio da Realização da Receita subordina o seu reconhecimento a quatro requisitos: preço objetivamente definido, completo desenvolvimento das fases relevantes necessárias por parte da entidade para estar atingido o mérito da receita, aquisição do dinheiro ou da quase certeza de recebê-lo e conhecimento dos valores das despesas necessárias à obtenção de tal receita para sua concomitante contabili- 
zação. Com tais restrições ao reconhecimento da receita, tem-se, como conseqüência, grandes restrições ao registro de certos ativos ou ao registro de mutações no seu valor de mercado.

Com isso, com o crescimento dos elementos patrimoniais sendo trazidos a seu valor justo, criou-se o problema de, muitas vezes, tais valores justos provocarem aumentos de ativo sem que aquelas condições para reconhecimento das receitas estejam completadas. Para solucionar essa situação criou-se uma nova visão da relação entre patrimônio líquido e resultado: um conjunto de contas dentro do patrimônio líquido que servem para registro das mutações dos elementos ativos e passivos em termos das variações de seus valores justos, para trânsito por resultado apenas posteriormente, quando aquelas quatro condições para o reconhecimento da receita estiverem presentes.

$\mathrm{O}$ ajuste dos títulos classificados nas instituições financeiras como "disponíveis para venda" é um clássico exemplo: esses ajustes são registrados diretamente contra uma conta do patrimônio líquido e só transitam pelo resultado (e obrigatoriamente efetuam esse trânsito) quando de suas negociações ou de sua mudança para a categoria de "em negociação".

Tem-se, assim, a figura dos "Lucros Não Realizados" dentro do Patrimônio Líquido, como contrapartida a esses ajustes de ativos e passivos a seus respectivos valores justos, a transitarem pelo Resultado apenas quando "Realizados". Com isso, criou-se um mecanismo novo que precisa ser bem entendido e absorvido pelos usuários das demonstrações contábeis. E, para ter-se a melhor evidenciação dessas movimentações é que se criou a Demonstração do Comprehensive Income nas normas norte-americanas e também nas do IASB.

É interessante, mais uma vez, citar os autores Edwards e Bell que, há 45 anos, tinham já desenvolvido um modelo até mais completo do que esse para ajuste de todos os ativos e passivos a seus valores correntes (corrigidos pela inflação)! Só que com todos os ajustes transitando pelo re- sultado, mas com esse dividido em duas partes: a realizada e a não realizada!

O problema, mais uma vez se salienta, é que nos moldes atuais nem todos os elementos patrimoniais do ativo e do passivo estão trazidos a seu "valor justo"; alguns estão sendo ajustados de forma obrigatória, como nos instrumentos financeiros citados ou nos produtos biológicos como nas regras do IASB, e outros ajustados apenas de forma optativa, como na reavaliação dos ativos imobilizados, certos intangíveis etc.

Pior ainda, têm-se sofisticações como instrumentos financeiros e ativos biológicos a seus respectivos valores de mercado, o que significa estarem a valor presente, mas o imposto de renda diferido ativo e passivo ainda registrado pelos seus valores futuros, nominais, sem quaisquer ajustes a valor presente.

E, no Brasil, há a experiência, nem sempre muito agradável, dessas avaliações com fundamentações diferenciadas, como é o caso do grave problema das opções no tratamento das reavaliações de imobilizado: algumas empresas adotam esse princípio e efetuam tais reavaliações pelo menos a cada quatro anos, outras (sociedades não abertas) a efetuam quando querem. Ou então as reavaliações se dão apenas nos itens do imobilizado que se escolhem para esse fim, não necessariamente abrangendo todo esse grupo de contas; ainda, os métodos para cálculo desses valores são discutíveis, como ao se avaliar imóveis pelo custo de se fazê-los novos hoje, com a dedução de uma depreciação linear; e essa depreciação calculada com base num valor residual tomado como nulo, como fiscalmente admitido, como se isso representasse a melhor maneira de se chegar a seus valores de mercado.

Vê-se, assim, que se está, de fato, numa fase evolutiva bastante delicada, com ampliação das alternativas de critérios de avaliação, com desvinculação entre base para balanço e base para resultado etc., mas sem um modelo completo que sirva de guia no horizonte.

\section{UMA ANÁLISE REALISTA}

O conceito e a aplicação de Valor Justo representam, sem dúvida, uma espetacular, agressiva e, de certo modo, algo arriscada virada no que se refere à avaliação contábil.

Espetacular, pois os órgãos reguladores até tomam a dianteira com relação aos scholars na defesa e no enforcement dessa nova e revolucionária forma de avaliação. As Estruturas Conceituais Básicas deveriam, assim, ser alteradas e emendadas.

Agressiva, pois coloca o Fair Value em lugar de e não em complemento a algo que já existe e que vem há séculos nas demonstrações contábeis como forma principal de avaliação, ou seja, o custo histórico como base de registro inicial (com sua variante custo histórico corrigido). Passa por cima, até, do custo corrente e do custo de reposição, alternativas mais conhecidas dos contadores.
De certo modo arriscada pois, ao apagar-se o registro histórico para, em seu lugar, colocar-se ativos e passivos avaliados pelo valor justo, estar-se-á dificultando o tracking entre competência e fluxos de caixa. Por outro lado, o grau de subjetividade dos cálculos de fluxos descontados, quando não existir mercado ativo, beira quase a não aceitabilidade, sob o ponto de vista de um mínimo de objetividade e consistência.

Por que, então, não se partir para uma estruturação planejada a longo prazo, mas, até que se chegue lá e se tenham pesquisas empíricas validando as mudanças, seguir um caminho apenas um pouco mais trabalhoso, mas provavelmente muito mais informativo e com uma visualização muito mais ampla dos efeitos dos diferentes critérios assumidos de valoração, mantendo-se as duas bases 
de avaliação? Por que não se ter os elementos patrimoniais a seus valores objetivos históricos (com a correção quando sua ausência trouxer deformações) numa coluna, e numa outra a seus valores justos? Ter-se-ia, na primeira, a objetividade da informação dos valores aplicados nos ativos, dentro do pressuposto de que essas aplicações gerarão valores no futuro que recuperarão esses valores investidos e ainda lhes agregarão valor, gerando, então, lucros, com a prudência de reconhecer esses lucros apenas quando de efetivas condições que the permitam o rótulo de "realizados". E ter-seiam, na segunda coluna, todos esses mesmos elementos (e até alguns não incorporados pela contabilidade a valores históricos, como o goodwill, por exemplo) a seus "justos valores". Poder-se-ia até exigir o registro do custo do capital próprio nesse segundo caso (e aplicado ao patrimônio líqui- do a valores ajustados, e não ao seu valor original histórico), com o cálculo do lucro residual, ou do valor econômico agregado, numa forma muito mais avançada. Isso corrigiria essa lamentável ausência de registro, hoje, na contabilidade, do custo de oportunidade do capital próprio; só que se o teria aplicado sobre o capital próprio tentativamente medido a seu valor justo e não como se faz o cálculo desse indicador hoje, sobre o patrimônio líquido investido pelos sócios, a valores históricos (eva $\left.{ }^{\circledR}\right)$.

A mistura atual de valores e o incremento dessas alternativas não estão resolvendo os problemas de avaliação da contabilidade a custos históricos e talvez estejam criando uma complexidade não acompanhada de todos os possíveis benefícios que esses valores adicionais podem propiciar.

\section{SUGESTÕES}

Preconiza-se, então, que, em primeiro lugar, a definição padrão de Valor Justo seja alterada para algo mais objetivo. Valor Justo seria, assim, o valor de mercado, definido como o quanto se deveria desembolsar no mercado para que uma entidade adquirisse 0 ativo objeto de avaliação, aproximadamente no mesmo estado em que se encontra.

Preconiza-se, também, que, como método preferencial para calcular o valor justo conforme acima definido (se não existir um mercado ativo), antes de se entrar com cálculos de fluxos descontados, se procure calcular o custo corrente dos insumos contidos no ativo objeto de avaliação ou através da criteriosa utilização de índices de preços específicos. Somente em último recurso, recorrer-se-ia a cálculos matemáticos probabilísticos.

A Introdução do Valor Justo representa, sem dúvida, significativo avanço nas práticas contábeis. Entretanto, a fim de não provocar reações exacerbadas, seria interessante tornar mais objetiva sua mensuração e introduzi-lo nas demonstrações contábeis em quadros suplementares, ou ainda em notas explicativas, pelo menos até que a prática se consolide. Aliás, talvez um bom modelo fosse esse: demonstrações com objetivos diferentes calcadas em avaliações diferentes. Essa formatação poderia permitir inclusive uma avaliação multicolunar: elementos de balanço e de resultado a valores originais (históricos), a valores de reposição e a valores de mercado (ajustados ou não pela inflação, conforme a relevância da influência da mutação do poder aquisitivo da moeda).

Ou seja, sugere-se que tais avaliações adicionais durante um período de transição sejam evidenciadas em complementação às tradicionais e não pura e simplesmente as substituindo. Haveria até uma base de comparação interessante. E daí pesquisas empíricas poderiam, dentro da Teoria Positiva da Contabilidade, ajudar, de maneira objetiva e mais fundamentada, a escolher os melhores caminhos. Sem, entretanto, perder-se de vista, como se fosse uma âncora, os critérios tradicionais que, de tão validados por séculos de experiência, não devem ser substituídos enquanto não comprovadas, empiricamente, as alternativas.

Pesquisa empírica essa que deveria olhar todos os ângulos: o interesse e a utilidade das informações para seus usuários, a viabilidade, a praticabilidade e o custo da obtenção dessas informações, eventuais problemas estratégicos derivados da sua produção e divulgação pelas entidades, bem como a viabilidade, objetividade e o custo de sua auditoria.

Não se pode esquecer que a Contabilidade, conforme ludícibus (1978), é um árduo exercício para equilibrar Relevância, Objetividade e Praticabilidade de um determinado procedimento. Se se atribuir peso cem à relevância e zero aos demais parâmetros, no limite extremo, se estará fadado ao fracasso. Dessa forma, obter-seá zero também em Relevância, pois o procedimento não será implementado. A Contabilidade não é um modelo voltado primariamente para a avaliação do valor da entidade (embora possa muito ajudar nesse sentido), mas um modelo alocativo de recursos, que devem ser controlados e de cuja utilização deve-se dar a maior accountability possível. Assumir essa tarefa adicional de prover valor é mesmo uma função viável, mas sem abandonar a que a originou. Deixe-se aos investidores a utilização dos modelos finais de avaliação e a decisão sobre qual ou quais devam, no futuro, ser praticados. 


\section{Referências Bibliográficas}

EDWARDS, Edgard O.; BELL, Philip W.. The Theory and measurement of business income. Berkeley and Los Angeles: University of California Press, 1961.

KPMG, Insights into IFRS. Edição'2005/2006, Thomson, 2005.

IUDICIBUS, Sérgio de. Análise de Balanços. São Paulo: Atlas, 1978.

Teoria da Contabilidade. 7a. ed. São Paulo: Atlas, 2004.

; MARION, José Carlos. O Dicionário de Termos de Contabilidade. São Paulo: Atlas, 2001.

; MARTINS, Eliseu; CARVALHO, Luís N. Contabilidade: Aspectos Relevantes da Epopéia de sua Evolução. São Paulo. Revista de Contabilidade e Finanças da USP, n. 38, 2005.

LISBOA, Lázaro P.; COSTA, Fábio M. da; PIGATTO, José A. M.. "Valor Justo" em Contabilidade. Anais do XVI Congresso Brasileiro de Contabilidade, 2000.

MARTINS, Eliseu. Avaliação de Empresas: Da Mensuração Contábil à Econômica. São Paulo: Atlas, 2001.

\section{NOTA - Endereço dos autores}

Pontifícia Universidade Católica de São Paulo Rua Monte Alegre, 984 - Perdizes

São Paulo - SP

05014-901
Universidade de São Paulo

Faculdade de Economia, Administração e Contabilidade

Departamento de Contabilidade e Atuária

Av. Prof. Luciano Gualberto, 908

São Paulo - SP

05508-900 